\title{
Recovery on the Pitch: Street Football as a Means of Social Inclusion
}

\author{
Esther Ogundipe $(\mathbb{D} \cdot$ Marit Borg • Tommy Thompson • Tor Knutsen • \\ Cathrine Johansen $\cdot$ Bengt Karlsson
}

Received: 1 May 2020/ Accepted: 10 July 2020/Published online: 23 July 2020

(C) The Author(s) 2020

\begin{abstract}
The study contributes to the existing literature on the value of street football teams in recovery, by exploring how persons with mental health and/or substance abuse problems experience participation in street football teams. In total, 51 persons experiencing mental health and/or substance abuse challenges who played in street football teams, in Norway, participated in focus group interviews. The interviews were recorded and transcribed verbatim. Data were analyzed using thematic content analysis, and resulted in three major themes: (1) The spirit of the football team, (2) More than just a pitch, and (3) The country's best follow-up system. Overall, our findings highlighted the importance of community and communal efforts through acts of citizenship, in facilitating and promoting social inclusion for persons in challenging life situations. Street football is one measure than can be helpful in this context. Communities, policy makers and funders need to acknowledge and gain more insight and understanding of the value that street football teams represent. There is also a need for further studies exploring what contributes to community in our highly individualistic society.
\end{abstract}

E. Ogundipe $(\varangle) \cdot$ M. Borg · T. Thompson ·

T. Knutsen · C. Johansen · B. Karlsson

Faculty of Health and Social Science, University of

South-Eastern Norway, Drammen, Norway

e-mail: Esther.Ogundipe@usn.no
Keywords Social recovery - Social inclusion . Community participation · Citizenship · Streetfootball teams $\cdot$ Qualitative participatory methods

\section{Background}

What matters in recovery is not whether we're using services or not using services; using medications or not using medications. What matters in terms of a recovery orientation is, are we living the life we want to be living? Are we achieving our personal goals? Do we have friends? Do we have connections with the community? Are we contributing or giving back in some way?" (Attributed to Pat Deegan [36]).

Recovery, social inclusion and human rights are increasingly recommended in national and international guidelines for mental health and substance abuse services [9, 24, 51]. Although recovery in western health and welfare services is evolving, the individualized and clinical understandings are still dominating [34]. The additional aspect of the journey that involves everday life, the contribution of other persons, the community, societal and interpersonal contexts, namely social recovery, is often overlooked [34, 42, 45]. There are several characterizations of social recovery [1, 34]. Social recovery takes into account the person's social contexts [1]. Thus, the 
impact of culture and the structural elements of our socio-economic-political system is seen as relevant [35]. The concept of social recovery demands for health services, policy makers and practitioners to look beyond the person, and consider issues of social justice and social inclusion [11]. Another way of understanding social recovery, is by referring to what is essential to us all as human beings; being loved, being with others, loving someone and having fun [24]. Central in social recovery is that the person is first and foremost seen and understood as a citizen, living in the community and being an active agent in his or her life processes as opposed to a victim of a disease [24].

\section{Social Recovery and Social Inclusion}

Social recovery is often discussed in tandem with social inclusion, and Ramon [34] made the case to look at these concepts consistenly alongside each other, in order to avoid a too narrow understanding of the concepts and their significance. Underpinning this paper is an understanding that social inclusion entails, amongst other things, having the opportunity to participate in the community and to experience citizenship [19, 49]. Social recovery as "Active community participation" calls for actions and collaborations regarding issues that stand in the way of the person's recovery processes and opportunites to participate and contribute to the local and wider community [24]. Citizenship within social recovery can be understood as: "promoting the rights, responsibiltities, roles, resources and relationships of persons with mental health problems, along with a sense of belonging that is validated by other citizens" [14], p. 1). The concept "Acts of Citizenship" is used to clarify what social recovery means for the person, the professionals, the knowledge base and the service development [20]. In this paper, we discuss social recovery in tandem with two aspects of social inclusion, namely community participation and citizenship.

Enhancing Social Inclusion Through Sport

Sport as means of bringing people together and promoting social inclusion has received a growing attention in mental health and substance abuse services [1, 29, 38]. Benefits of sport participation at the invidual level may entail improved self-esteem, physical wellbeing and mental health. At a group level: crime prevention, education, community development and integration [39].

An area of sport with growing attention is what is called street football (or soccer). Street football offers an excellent opportunity to foster a sense of inclusion for marginalized groups [28], such as people who experience mental health and/or substance abuse issues, or other people who experience social exclusion. The aim behind street football sessions is to increase people's self-esteem, mental health, physical health and quality of life.

The study of Benkwitz et al. [2] on street football, highlights how street football sessions have the potential to enhance recovery as well. Their findings demonstrate that street football has considerable links to the five recovery processes conceptualized as CHIME: Connectedness, Hope and optimism, Identity, Meaning and purpose and Empowerment [27]. Following the positive benefits of sport participation for social inclusion and recovery, several different sport-based programs have emerged, such as street football (or soccer) programs [28]. Although limited, the body of knowledge on street football offers some important findings [28]. Furthermore, the study of Benkwitz and Healy [1] on street football shows how it has the potential to support active citizenship processes, which could further increase levels of social capital and enhance social identities. They noticed that more work is required to further explore the contextual impact of poverty and employment, and the role that football (or sport) can potentially play. Magee and Jeanes [30] studied a group of young male homeless players from the United Kingdom who attended The Homeless World Cup. They recognized that some of the benefits of attending the tournament were that players got motivated to be physically active and experienced an increase in self-esteem and personal dignity. They also noticed some challenges and difficulties. At times the street football players felt overwhelmed and embarrassed after losing games by significant scores. In a similar fashion, Macnaughton and Meldrum [28] found both tension and positive contributions of participating in street football programs. Being on the field helped players build confidence and life skills through sport. On the other hand, when expectations and responsibilities placed on players exceeded their skills-set, this could lead to 
negative experiences. Welthy Peach et al.'s [50] study investigated the impact of street soccer USA on its volunteers and observed that interactions between players and volunteers built increased understanding and community cohesion. Friedrich and Mason's [17] literature review on street football programs for people with mental health problems revealed that street football programs were very different in cultural context, target groups, location and in terms of the people involved. They concluded that there is a need for more studies exploring the potential football (or sport) may have as a viable option for adjunct mental health treatment. At the same time, one needs to consider the complexity and context [40].

\section{The Norwegian Context}

In Norway «street football» is a concept used for football specific activities and projects to support recovery for people with mental health and/or substance abuse challenges. Street football is organized in partnership with ordinary football clubs, and in many places also in collaboration with mental health and substance abuse programs and other health and welfare services. In 2011, the first Norwegian street football team emerged [44]. Currently, there are 21 street football teams in Norway [43]. A common organization called "The Football Association" organize matches, tournaments and support in a variety of ways. The Football Association is also supporting the teams through funding and promotion through media and political initiatives. Their goal is to facilitate a meaningful everyday life for the players. The street football teams are regarded as a low threshold activity, where anyone with a mental health and/or substance abuse problem can participate. No distinction between gender or age is made. Everyone is welcomed. In many of the teams professionals from various health and welfare services attend training and matches regularly. In this way services become accessible and availale in a more efficient way than traditional practices. Breakfast or lunch is organized at trainings and matches to make sure the players get a proper meal [43].

There are few studies on street football teams in a Norwegian context. Those conducted support the international literature. A key finding in Mikalesen and Tonholm's [32] research is that players had positive experiences of participating in the street football team because it provided them with a meaningful everyday life and the chance to develop new coping skills. In another study by Hystad [23] several ways of participation within a street football team were identified. On one side there is a group mentality that is about protecting one another, and values such as trust, friendship and unity are of great importance for the players. On the other hand, some situations threaten these values. The findings also reveal that the players were proud of being affiliated with the club the street team belonged to. At the same time, being affiliated with the club and the club's community required discipline from the players.

\section{The Study}

Despite the growing interest in street football amongst researchers, there are few studies that illustrate how such programs influence social recovery and social inclusion [28, 39, 47]. The objective of the present study was to describe and explore how persons with mental health and/or substance abuse challenges experience participation in street football teams. The research question was: What experiences do players have with participation in street football teams in relation to their recovery processes?

\section{Methodology}

Collaborative Research

The collaborative study was carried out by a research team consisting of seven people, four with research experiences and three were players in street football teams. A competence group involving researchers, members of street football teams and the Football Association advised the research project throughout the process. The intention of the group was to facilitate collaboration, and include different perspectives throughout the project period. Discussions were focused on interviews and interview guide, recruiting, analysis and dissemination. This was done in order to foster a more inclusive participation in the process of knowledge development $[3,5]$. 
Qualitative Method

Two-stage focus group interviews [22, 31] were carried out in four street football teams between May 2018 and September 2018. In total eight focus group interviews were conducted. The interviews took place at the site the participant themselves chose. Typical places were the club facilities like meeting rooms or club-canteen. Having the interviews within the club premises, gave the researchers the opportunity to become acquainted with each club's work, history and activities. We got to see pictures of past heroes and news coverage. We admired medals and trophies the teams had won, as well as well known football players and other key persons in the teams. This helped to contextualise the interviews.

\section{Recruitment and participants}

The participants were people experiencing mental health and/or substance abuse problems, who play in street football teams. The participants came from four different football clubs in eastern Norway. They were recruited with the support of a contact person at each of the four football clubs.

In total, 51 persons participated in the interviews. The majority of participants were men $(n=48)$ and only three women took part. There was a wide range in age, with most of the participants being between 40 and 50 years. All were over the age of 18. About half had a boyfriend/girlfriend or were cohabitants, and the other half were single. The majority were Norwegian citizens and had a high school diploma, undergraduate degree or a postgraduate degree. Nearly $20 \%$ worked full-time, the others mentioned volunteer work and other activities. There was a wide range in regards to how long the participants had played in street football teams. Many of the participants mentioned that they had contact with both the specialist services, municipal services and service user organizations.

\section{Analysis}

The eight focus group interviews were transcribed verbatim, resulting in 103 pages of text. The text was analyzed using thematic content analysis $[4,25]$. The analysis was done by the second and third authors. The content analysis was conducted in the following four phases, for each of the eight interviews:

\section{Phase 1}

To begin with the second and third author read each interview in order to gain an overall impression. In this phase, they focused on seeing similarities and contrasts in each interview, and being reflexive when it came to their own understanding [25].

\section{Phase 2}

In the next phase, they wrote down preliminary ideas and themes related to the data that appeared to be meaningful for answering the research questions. These were then organized as meaning-bearing units, with quotations that substantiated the meaning. The meaning-bearing units in the interview were compared to one another and gathered in tentative codes. Both authors prepared a written tentative analysis [25].

\section{Phase Three}

Phase three, consisted of two joint analysis meetings. At the meetings they worked to look at what appeared to be common and what was different in their respective tentative analysies. In the analysis meetings, it became important to challenge themselves and each other regarding how data could be understood and how their own pre-understandings came into play [25].

\section{Phase Four}

In phase four, the last analysis meeting between author two and three occurred. They presented their final proposals to each other, and discussed similarities and differences, before coming to a final interpretation of findings [25].

\section{The Competence Group}

The final anlysis was presented for discussion in the competence group. General reflections, reflectivity and contextualization were emphasized. The members of the competence group understandings and preunderstandings of phenomena and themes were considered. This lead to nuances, elaborations and more reflections on the material, analysis process and findings. The advantage of having several researcher working closely together is that one can help each 
other, by focusing on how preunderstandings may matter rather than discussing if it does so. Reflectivity presupposes a critical self-reflection on how the researchers' own background, history and understandings influence the entire research process. It involves knowledge and awareness of how researchers interpret and construct their findings $[15,16]$.

Ethics

The study was reviewed and granted ethical approval by the Norwegian Centre for Research Data. All participants were informed about the study's background and objects via written information, and through oral information from the researchers, prior to signing a consent form. They were informed about their rights to withdraw from the study at any time, and that they could request that their information be deleted in that case. The paper is written in a way that will protect the anonymity of the participants.

\section{Findings}

The intent of the study was to describe and explore how persons with mental health and/or substance abuse problems experience participation in street football teams. The analysis resulted in three themes: (1) The spirit of the football team, (2) More than just a pitch, and (3) The country`s best follow-up system.

The Spirit of the Football Team

This theme highlights participants' experiencies with being in street football teams, and the role the teams and coaches played in the person's recovery processes. The participants offered unique understandings of what it meant to be a part of street football teams. They talked about growing friendships, common engagement, getting together around the lunch table, and other things that they were sharing in this exceptional community. The fact that the street football players had similar backgrounds as service users, was helpful as it allowed them to be their true authentic selves. One participant said: "You can be yourself. You don't need to pretend. If you have a bad day, then you have a bad day. You do not need to pretend". Within the street football teams, they freely shared their stories without so much shame and guilt. Being able to do so felt liberating. Participants also talked about positive life experiences. For example, in one team, many of the players had become fathers. Talks about fatherhood thus emerged as a natural talking point. One said: "I have started a family. A lot of the players here have toddlers that are at the same age. That is very good". Being able to be their true authentic selves and being in a team where players supported each other in the ups and downs of life, was experienced as valuable. There were many examples of giving and receiving support in this community. In one team, some players needed to be picked up at home before training. One of their teammates had just got his driving permit back and volunteered to pick them up. The teammate with the driving permit underlined how important it was for him to be able to help others, contribute and give something back:

“It's a good feeling, ... I feel like I'm in the right place. I'm on time, I pick them up, and then we come here. Just like someone else did for me some time ago. Now I can do it for someone else. It is a good feeling. It's just nice. You feel like you are being responsible."

Another positive aspect of being in a team was the opportunity to be missed. If someone did not attend training or was gone for several days, the other players would usually check on the person via a text message. They usually wrote: "We missed you at training". If the player still did not show up after a couple of text messages, they left the person alone. They explained that the person had to make their own choices about life:

"Well it depends on what he wants. Does he want to come back, or stay away? Right. So, yeah. We can send a text message that we miss you, or ask if you are coming to training and stuff. But we can't do more than that. I can't go to his house and pick him up if he doesn't want to. We can't do that."

The importance of making choices was also conveyed when asked how the street football had impacted upon their recovery process:

"Everyone has to decide what they want to do for themselves. If you want, then you can get help to, for example, I got a job in a football club. So that's kind of what you want and what one is 
ready for. There is actually many opportunities.

And actually a lot of help."

The coach was an important part of the team. According to the participants, the coaches contributed in a variety of ways making the team predictable and safe. Participants explained that it was important that coaches prepared and set the agenda, had expectations and at the same time were aware of each person's situation. The participants described how the coaches had specific expectations about showing up, making an effort and doing your best. Doing your best both related to the football and the social relations with fellow players. The players knew that the coaches believed in them. "I've never been so reliable in my life" said one participant. When we asked if this particular expectation had an impacted on their recovery process, one said: "Yes in a positive way. Because you go here, you have a duty to attend. And then you get a few hours during the day where you can get a break". The coaches" expectations contributed to street football being seen and experienced as something meaningful and serious.

The coach also expected them to meet up clean and sober. This was also important for the participants' recovery process, as feelings of security were amongst many things related to the fact that it was not allowed to talk about drugs. One participant said this: "No drugs. You can train three times a week with good coaches, and hang out with the guys in the team. So, for me it has been good". Another participant said: "It is better to play football than to walk around and use drugs. Right. Everything is better". Clear and understandable expectations from the coaches as well as fellow players, contributed to the street football teams being a safe haven. Team spirit and respect for the team as well as others emerged as a particularly important topic.

\section{More than Just a Football Pitch}

This theme captures participants' experiences with being on the pitch, and the benefits and challenges that followed. We noticed that the pitch was a training ground for more than football, and identified two key processes: the sporting and the social.

The first process, the sporting, provided the participants with opportunities to experience mastery and knowing that the body works, which was viewed as vital in for one's recovery journey. They reported feeling good about getting fit. Many had a passive lifestyle and found it liberating to feel stronger and breathe better. Several participants also talked about becoming better football players. One participant said this: "I feel better on the field at least. I feel like I have become a better player. Much better player". Better football players resulted in an increase in the level of skills in the team. When this occurred, the winning instinct emerged, and being okay with losing a game could be challenging at times:

"I think the problem is that in recent years the street football teams have become very competitive. There has been a shift away from unity and things like that. Now it is like, well for me ... I hate to lose. There is nothing worse than losing. So when I go out on the pitch, just like when I played fourth division as a teenager, and now when I'm play street football, then I go out there to win."

Several participants explained that once they were on the pitch it was all about winning. This consequently meant that some players were put on the bench, and not given as much time to play, and in turn experience mastery. Being competitive on the pitch had its pro and cons.

The second process, namely the social, reveals how the pitch had impacted the players' social life. One offered some reflections on how selfish one becomes as a person with drug problems: "You tend to only think about yourself. But on the football pitch you are a part of a team and you need to pay attention to the team's and co-players" needs and preferences". Another participant said: "If someone is having a hard time, then we try to encourage him. That's kind of the point". On the pitch they had the opportunity to learn and practice togetherness with other people. This entailed amongst other things, learning to disagree without being disagreeable. On the pitch they could try and fail in a safe place. These experiences were useful lessons for participants to bring along and use in other settings, such as work life, family life and other social places. Being with others who had similar lived experiences facilitated contexts for developing human realtionships and social skills. 
The Country's Best Follow-Up System

This theme focuses on participants' experiences of street football as a viable option for treatment. Street football offered experiences of a meaningful everyday life. Some had been passionate about football since they were kids. One participant said: "Yes, I have always liked football. And especially the club here. I have always supported this club. So I think this is a very good service". For others, it was about having something to go to, meet others or get fit. One described it like this: "It makes life a little more meaningful, to put it that way. And yes it, it is very important not to just sit at home, or else one might go out and start using drugs again". The need for a follow-up system and a safe environment as a part of the social recovery process was emphaized. Many criticized how they typically had been left to themselves after treatment without meaningful and tailored follow-up services:

“There isn't a lot of options ... at least not here. This municipality doesn't have that much to offer. In regards to follow-up systems or ... like services after being released from jail, or treatment. It is important to have something else, a place to go. They have self-help groups, but nothing else. I think this [street football] is a fucking good service."

The participant praised the ways the street football teams collaborated with a variety of health and welfare services, such as mental health and substance use services, NAV [Norwegian Labour and Welfare Administration] and other programs. Having professionals from these services present on the football pitch was seen as very important. These were professionals who had street football teams on their list of duties. In some places, professionals would join lunch, which contributed to them becoming more familiar, and 'harmless', which in turn made it easier ro raise issues: "We can get help with filling out applications, stuff like that. It can be done after traning, and if problems have emerged, then it is addressed immediately. That is also very important. It gives a sense of safety". Another participant said: "Everything from living situation to, or if something else comes up then it can get addressed right way, you get help. Something gets put in motion". A third participant said: "It is nice to not have to jump through so many hoops".
Working with professionals on the pitch, outside the services and offices were experienced as very different. The participant felt that the services could learn something from the way the street football teams were organized, and how the teams provided people with opportunities and accepted that things take time.

More recognition of street football teams within the services was deemed as necessary, because some participants had only coincidently heard about the street football teams in services:

“But this kind of service isn't well known. I heard about it randomly. I was hospitalized, when one told me: 'I think he plays football or something on a team'. I asked for more information, but the person had no further information. So it was kind of random. I've been here since I found out about it. But that's a bit like ... this is Norway best follow-up system, in my opinion. It's a shame it hasn't been around for longer."

Making street football more visable in the society was also understood to be important. One said: "we must become more accepted in society". While another participant said: "Why isn't there more services such as this? It's all politics!". Participants" experiences of being excluded from the society, made being a part of a recognized football club even more important.

\section{Discussion}

Our research question sought to describe and explore street football players', with mental health and/or substance abuse problems, experiences of participation in street football teams in relation to their social recovery process. In the discussion, we elaborated on our findings, with reference to the previously introduced terms "Active community participation" and "Acts of citizenship".

\section{You Will Never Walk Alone}

Recovery can be seen as a process of restoring a meaningful sense of belonging to one's community [12]. Seeing recovery as a social process involves recognizing everyday life, which includes meaning, living conditions and one's community, as central to 
recovery [6]. Reintegration into community should not fall on the individual person's efforts alone. A recent study by Brekke et al. [8] highlighted the need for communities to do more to emphasize the central aspects of social recovery for persons experiencing mental health and/or substance abuse challenges. They further, suggested that genuine community participation might be a missing piece in the promotion of social recovery, and that services should be acting as a link to the community. Despite this well known knowledge, western mental health and substance abuse services continues to prioritize an individual understanding of recovery [34, 42, 45].

Our findings emphasized the importance of community and facilitating caring human relationships in social recovery. The street football teams played a key role in these areas. Together as a team in a safe environment, the players could share their experiences, learn from each other and support each other. The coach was an important part of the team. They had specific expectations of the players, showed in concrete ways that they cared and supported the players in a variety of ways. The professionality of the coaches and being a part of a real football club, contributed to experiences of meaning and belonging and that what they were doing was serious and important both for themselves and others. The importance of having a meaningful everyday life in one's recovery process is well established. There is still a need to focus on "normal" enviroments and activites, such as street football. Furthermore, these kind of enviroments and activities, should be priotized in health and welfare programs' agendas $[6,33]$.

\section{Little Things can Make a Big Difference}

Acts of citizenship involve the practice of the making of citizens. At the heart of acts of citizenship is the claim for justice in the face of injustices experienced by citizens (Hamers et al. 2019). Hamers et al. (2019) described how mental health workers' inclusive actions often entailed bending, or breaking, the existing rules and norms of clinical practice. Service users regarded mental health workers as champions of social inclusion, enhancing their status as citizens and full and equal participants. The value of acts of citizenship is not new and has previously been referred to as the meaning of "little things" within the recovery literature [46]. A recent literature review on the construction of helpful relationships between service users and health professionals, further underlined how "little things" seem to be an invisible but effective part of recovery-oriented practice [46]. In our study, "little things" - acts of citizenship, within the street football teams were of great importance for the participants' experiences of meaning, community and friendship, all seen as of key value in their recovery process. Some examples of these acts, were players' willingness to share life experiences and give support, by for instance picking up mates on the way to the pitch. The ability of the coaches to see each player and respect individual differences, have expecations, and their inclusive actions, reflected in their ability to create good and safe team spirit were also underlined. Our findings support what has previously been noted, that street football sessions have the potential to support active citizenship process, increased levels of social capital and enhance social identities [1].

\section{Together on the Pitch}

The UN Special Rapporteur called for more awareness that health improvements requires measures on the societal level [48]. Street football is one of several measures that can be helpful in this way, as revealed in the findings of this study. Another way the community in the street football team supported the participants' social recovery, was that they together on the pitch had the opportunity to develop human relationships and social skills that could be useful to other areas in life. Similarly, Tonholm [44] discussed how participants in a Norwegian street football team experiences with being on the pitch had a positive effect in other areas of life. In a similar fashion, Lamont et al.'s [26] study showed how participating, exercising and playing matches were a key motivating factor for making changes in other areas of life. Clark [10] referred to football as a metaphor for learning to cope with life, living with mental health and substance abuse problems and maintaing one's own health through recovery. Furthermore, Clark [10] described how playing football in general, and street football in particular, can be experienced as a social and therapeutic activity. Football in this context was therefore seen as a very important contribution to social connection, the development of human communities and experiences of good health. For our participants, developing portable skills, experiencing mastery, personal 
growth, better physical and mental health over time, together on the pitch, were deemed as valuable experiences for their recovery process. The importance of a recovery nurturing environment has previously been echoed as central for recovery [7, 13, 41]. The characteristics of a nurturing and supportive community meant being around persons who convey hope, are available when needed, demonstrate empathy and respect, provide opportunitites that engage one's active sense of self, and who resist taking on paternalistics roles that invite passivity [7, 18]. The characteristics of a nourishing communion are made up of acts, which corresponds to the definition of an act of citizenship. Namely, actions that involve the making of citizens [20].

\section{Facilitating helpful partnerships}

Another main finding in this study was the way street football teams collaborated with various health and welfare services. Having professionals from these services present on the pitch made them appear more familiar and less "frightening", which in turn made it easier for our participants to raise issues of importance to them and receive help. Similar to the study of Welthy Peach et al. [50], having professionals participate in street football teams, builds an increased understanding and community cohesion between our players and services. Street football team's collaboration with health and welfare services corresponds to the actions and collaborations, social recovery as active community participation calls for. Namely, actions and collaborations regarding issues that stands in the way of the persons' recovery processes and opportunities to participate and contribute to the local and wider community [24]. The fact that professionals are present on the football pitch, for instance helping out during lunch, can be seen as acts of citizenship, because it made the players feel that they were seen as active citizens, and that they matter [7]. Standard health and welfare services can get a lot of inspirations and ideas for service transformation from street football teams.

The importance of community and communal efforts through acts of citizenship highlighted in our study, offers further support to the importance of everday life in experiences of social recovery [6]. Slade [37] stated that the most important role services play in recovery is to support everyday solutions for everyday problems. We argue that this focus should not just be directed to services, but the society as a whole. We find this to be important and urgent as there has been an increasing focus on what constitutes recovery-oriented health services, but less attention has been paid to what would constitute a recoveryoriented society [21]. Likewise, our participants wanted street football teams to be recognized not only in the services but society at large. It is crucial that communities, policy makers and funders gain a better insight and understanding of the value that street football teams can represent for recovery [17] so that more persons experiencing mental health and/or substance abuse can have the opportunity to choose to participate.

\section{Methodological Considerations}

Although this study makes an important contribution to the evidence base on the value of street football teams in social recovery, there are some methodological issues that should be considered when interpreting the findings. The study took place in a Norwegian context, thus providing a specific perspective on the findings, which may influence the transferability of the findings to other contexts. This, however, can be said for all contexts. It is also noteworthy that despite there being female players on the street football teams, our sample consisted mostly of males. The distribution in our sample mirrors the distribution of gender within the teams. Having more female players present in the focus group interviews may have offered a more nuanced understanding of the value of street football in recovery. There may also be reason to reflect on whether or not the researchers' backgrounds and positions had an impact on the data collected. Due to awareness that the researchers display a positive attitude towards recovery, social inclusion and street football teams, there is a possibility that the perspectives of those who hold negative beliefs about recovery, social inclusion and street football teams were under-represented. Considering the fact that the quotations were translated from Norwegian, and that translation is an interpretive process, it is also possible that one might have missed the informant's intended exact original meaning. 


\section{Implications for Practice and Research}

The value of street football teams described in the present study corresponds with previous research that claimed that sport can be used as a means of promoting social inclusion, and strengthens the importance of social recovery [28, 39]. This in turn supports the UN Special Rapporteur argument, that social measures are important for improving a person's mental health $[24,34,42,45,48]$. The present study speaks to the necessity of communities gaining more insight and understanding of the value that street football teams represent. Being a part of street football teams provided our participants with the opportunity to be with others, be loved, have friends and have fun. By highlighting these subjective experiences, and what this meant for our participants' process of recovery, this study contributes to establishing a body of evidence of the value of street football teams in recovery. It therefore helps to "make the case" to policy makers and funders that football has the potential to be beneficial for recovery $[1,17]$.

\section{Conclusions and Further Recommendations}

The aim of the study was to describe and explore street football player's, with mental health and/or substance abuse challenges, experiences of participation in street football teams in relation to their recovery process. The study showed a variety of ways where street football teams were used as a means to promote social inclusion, more specifically community participation and citizenship. On the pitch they had the opportunity to be with others, develop friendships, have fun and do something they felt was meaningful, which in turn supports our participants' recovery process. We therefore argue that communities, policy makers and funders should gain a better insight and understanding of the value that street football teams represents. As with the work of Tew et al. [42] and also Benkwitz and Healy [1], we recognize that there is still a need to know "what works" in terms of specific social recovery focused interventions that may enable processes of recovery and enhance social inclusion, as well as, social capital and positive social identities. There is also a need for further studies exploring what contributes to community in our highly individualistic society. Furthermore, a national mixed method study, which captures all street football teams, with an emphasis on examining results related to work, perceived improvement in mental health and substance abuse problems, living conditions and quality of life, is warranted. In addition, a "cost-benefit" study that compares participation in street football teams and their collaboration with services, with "treatment as usual" is also deemed as necessary.

Acknowledgements Open Access funding provided by University Of South-Eastern Norway.

Open Access This article is licensed under a Creative Commons Attribution 4.0 International License, which permits use, sharing, adaptation, distribution and reproduction in any medium or format, as long as you give appropriate credit to the original author(s) and the source, provide a link to the Creative Commons licence, and indicate if changes were made. The images or other third party material in this article are included in the article's Creative Commons licence, unless indicated otherwise in a credit line to the material. If material is not included in the article's Creative Commons licence and your intended use is not permitted by statutory regulation or exceeds the permitted use, you will need to obtain permission directly from the copyright holder. To view a copy of this licence, visit http://creativecommons.org/licenses/by/4.0/.

\section{References}

1. Benkwitz A, Healy LC. "Think Football": exploring a football for mental health initiative delivered in the community through the lens of personal and social recovery. Mental Health Phys Act. 2019;17:1-9.

2. Benkwitz A, Morris M, Healy LC. An ethnographic study exploring football sessions for medium-secure mental health service-users: utilising the CHIME conceptual framework as an evaluation tool. J Psychosoc Rehabilit Mental Health. 2019;6:55-65.

3. Beresford P. Public paarticipation in health and social care: exploring the co-production of knowledge. Policy Pract Rev. 2019;13(41):1-12.

4. Borg M, Askheim OP. Deltagerbasert forskning i psykisk helsearbeid -et bidrag til mer «brukbar» kunnskap? Tidsskrift for Psykisk Helsearbeid. 2010;7(2):100-10.

5. Borg M, Karlsson B, Hesook SK, McCormack B. Opening up for many voices in knowledge construction. Forum: Qualitative Social Research Sozialforschung (2012);13(1). https://nbn-resolving.de/urn:nbn:de:0114-fqs120117.

6. Borg M, Davidson L. Recovery as lived in everyday experiences. J Mental Health. 2008;17(2):129-41. https://doi. org/10.1080/09638230701498382.

7. Borg M, Kristiansen K. Recovery-oriented professionals: helping relationships in mental health services. J Mental Health. 2004;13(5):493-505. 
8. Brekke E, Lien L, Davidson L, Biong S. First-person experiences of recovery in co-occurring mental health and substance use conditions. Adv Dual Diagn. 2017;10(1):13-24.

9. Brekke E, Lien L, Nysveen K, Biong S. Dilemmas in recovery-oriented practice to support people with co-occurring mental health and substance use disorders: a qualitative study of staff experiences in Norway. Int J Mental Health Syst. 2018;12(30):1-9.

10. Clark L. Football as a metaphor: learning to cope with life, manage emotional illness and maintain health through to recover. J Psychiatr Ment Health Nurs. 2009;16:488-92.

11. Davidson L, O'Connell M, Tondora J, Styron T, Kangas K. The top ten concerns about recovery encountered in mental health system transformation. Psychiatric Serv. 2006;57:640-5. https://doi.org/10.1176/ps.2006.57.5.640.

12. Davidson L, Tondora J, O'Connell MJ, Kirk T Jr, Rockholz P, Evans AC. Creating a recovery-oriented system of behavioral health care: moving from concept to reality. Psychiatric Rehabilit J. 2007;31(1):23-31.

13. Deegan PE. Spirit Breaking: when the helping professions hurt. In: Spaniol L, Gagne C, Koehler M, editors. Psychological and social aspects of psychiatric disability. Boston: Center for Psychiatric Rehabilitation; 1997. p. 348-358.

14. Eiroa-Orosa FJ, Rowe M. Taking the concept of citizenship in mental health across countries: reflections on transferring priniciples and practice to different sociocultural contexts. Front Psychol. 2017;8(1020):1-11.

15. Finlay L. Phenomenology for psychoterapists: researching the lived world. United Kingdon: Wiley; 2011.

16. Finlay L. Five Lenses for the reflexive interviewer. In: Gubrium J, Holstein J, Marvasti A, Marvasti J, editors. Handbookof interview research. Thousans Oaks: Sage Publications; 2012.

17. Friedrich B, Mason OJ. "What is the score?" A review of football-based public mental health interventions. J Public Mental health. 2017;16(4):114-58.

18. Glover H. Recovery based service delivery: are we ready to transform the words into a paradigm shift? Aust e-J Adv Mental Health. 2014;4(3):179-82.

19. Hacking S, Bates P. The inclusion web: a tool for personcentred planning and service evaluation. Mental health Rev J. 2008;13(2):4-15.

20. Hamer HP, Rowe M, Seymour CA. "The right thing to do": Fostering social inclusion for mental health service users through acts of citizenship. Int $\mathrm{J}$ Mental Health Nurs. 2019;28:297-305.

21. Henwood B, Whitley R. Creating a recovery-oriented society: Research and action. Aust N Z J Psychiatry. 2013;47(7):609-10.

22. Hummelvoll JK. The multistage focus group interview - a relevant and fruitful method in action research based on a co-operative inquiry perspective. Norsk Tidsskrift for Sykepleieforskning. 2008;10:3-14.

23. Hystad J. Deltaking og samhandling på eit gatelag. Mastergradsoppgave i samfunnsarbeid. Avdeling for helseog sosialfag: Høgskulen på Vestlandet; 2017.

24. Karlsson B, Borg M. Recovery: tradisjoner, fornyelser of praksiser. Oslo: Gyldendal akademisk; 2017.

25. Kvale S, Brinkmann S. Det kvalitative forskningsintervju. Oslo: Gyldendal akademisk; 2015.
26. Lamont E, Harris J, McDonald G, Kerin T, Dickens GL. Qualitative investigation of the role of collaborative football and walking football groups in mental health recovery. Mental Health Phys Act. 2017;12:116-23.

27. Leamy M, Bird V, Le Boutilier C, Williams J, Slade M. Conceptual framework for personal recovery in mental health: systematic review and narrative synthesis. $\mathrm{Br} \mathrm{J}$ Psychiatry. 2011;199(6):445-52.

28. Macnaughton JFP, Meldrum J. Dreams of social inclusion: true experiences of street soccer through fictional representation. Creat Approaches Res. 2017;10(1):52-70.

29. Magee J. Disengagement, demotivation, vulnerable groups and sporting inclusion: a case study of the homeless world cup. Soccer Soc. 2011;12(2):159-73.

30. Magee J, Jeanes R. Football's coming home: a critical evaluation of the homeless world cup as an intervention to combat social exclusion. Int Rev Sociol Sport. 2011;48(1):3-19.

31. Malterud K. Fokusgrupper som forskningsmetode for medisn og helsefag. Oslo: Universitetsforlaget; 2012.

32. Mikaelsen F, Ogtonholm T. En for alle - alle for en! Et tiltak for å redusere sosial ulikhet $\mathrm{i}$ helse for rusavhengige $\mathrm{i}$ Fredrikstad og omegn. Høgskolen i Østfold: Rapport; 2012.

33. Nordaunet OM, Sælør KT. How meaningful activities influence the recovery process. Adv Dual Diagn. 2018;11(3):114-25.

34. Ramon S. The place of social recovery in mental health and related services. Int $\mathrm{J}$ Environ Res Public Health. 2018;15(6):1-14.

35. Ramon S, Healy B, Renouf N. Recovery from mental illness as en emergent concept and practice in Australia and the UK. Int J Soc Psyhiatry. 2007;53:108-22.

36. Scottish Recovery Network. Realising recovery: A national framework for learning and training in recovery focused practice (2007). https://scottishrecovery.net/wp-content/ uploads/2007/09/Realising-Recovery-Framework.pdf. Accessed Apr 2020.

37. Slade M. Everday solutions for everday problems: how mental health systems can support recovery. Psychiatric Serv. 2012;63(7):702-4.

38. Sherry E, Strybosch V. A kick in the right direction: longitudinal outcomes of the Australian community street soccer program. Soccer Soc. 2012;13(4):495-509.

39. Skinner J, Zakus DH, Cowell J. Development through sport: Building social capital in disadvantaged communities. Sport Manag Rev. 2008;11(3):253-75.

40. Smith A, Jones J, Houghton L, Duffel T. A political spectator sport or policy priority? A review of sport, physical activity and public mental health policy. Int J Sport Policy Polit. 2016;8:593-607.

41. Sommer M, Finlay L, Ness O, Borg M, Blank A. "Nourishing communion" A less recognized dimension of support for young persons facing mental health challenges? Humanistic Psychol. 2019;47(4):381-403.

42. Tew J, Ramon S, Slade M, Bird V, Melton J, Le Boutillier C. Social factors and recovery from mental health difficulties: a review of the evidence. Br J Soc Work. 2012;42:443-60.

43. The Football Association. (2019). https://www. fotballstiftelsen.no/om-oss/

44. Tonholm T. Målet med gatefotball er ikke rusfrie liv, men liv å være rusfri i (2017). https://forskning.no/kronikk- 
alkohol-og-narkotika-fotball/kronikk-malet-medgatefotball-er-ikke-rusfrie-liv-men-liv-a-vaere-rusfri-i/ 1162342. Accessed Apr 2020.

45. Topor A, Borg M, Di Girolamo S, Davidson L. Not just an individual journey: social aspects of recovery. Int J Soc Psychiatry. 2011;57(1):90-9.

46. Topor A, Bøe TD, Larsen IB. Small things, micro-affirmations and helpful professionals everday recovery-orienntated practices according to persons with mental health problems. Commun Ment Health J. 2018;54:1212-20.

47. Trussel DE, Mair H. Seeking judgement free spaces: Poverty, leisure and social inclusion. $J$ Leisure Res. 2010;42(4):513.

48. United Nations Human Rights Council. Report of the special Rapporteur on the right of everyone to the enjoyment of the highest attainable standard of physical and mental health. Geneva: United Nations (2017; 2019).

49. Ware N, Hopper K, Tugenberg T, Dickey B, Fisher D. Connectedness and citizenship: redefining social integration. Psychiatric Serv. 2007;58(4):469-74.

50. Welthy Peachey J, Cohen A, Borland J, Lyras A. Building social capital: examining the impact of street soccer USA on its volunteers. Int Rev Sociol Sport. 2011;48(1):20-37.

51. World Health Organization. Mental health action plan 2013 - 2020 (2013-2020). https://www.who.int/mental_health/ publications/action_plan/en/. Accessed Apr 2020.

Publisher's Note Springer Nature remains neutral with regard to jurisdictional claims in published maps and institutional affiliations. 